\title{
LA-ICP-MS studies of cross section of NiCrAIY-based coatings on high-temperature alloys $\dagger$
}

\author{
Andrei V. Izmer, ${ }^{a}$ Myroslav V. Zoriy, ${ }^{a}$ Carola Pickhardt, ${ }^{a}$ Willem Quadakkers, ${ }^{b}$ \\ Vladimir Shemet, ${ }^{b}$ Lorenz Singheiser ${ }^{b}$ and J. Sabine Becker ${ }^{* a}$ \\ ${ }^{a}$ Central Division of Analytical Chemistry, Research Centre Juelich, D-52425 Juelich, Germany \\ ${ }^{b}$ Institute for Material and Processes in Energy Systems, Research Centre Juelich, \\ D-52425 Juelich, Germany
}

Received 18th April 2005, Accepted 15th July 2005

First published as an Advance Article on the web 1st August 2005

\begin{abstract}
A microlocal analytical technique using laser ablation inductively coupled plasma mass spectrometry (LA-ICP-MS) was developed to investigate elemental diffusion at the interface of NiCrAlY-based coatings on high-temperature alloys. The surface of the cross section of alloyed sample was scanned with a focused laser beam (diameter of laser crater, $25 \mu \mathrm{m}$; wavelength, $213 \mathrm{~nm}$; laser power density, $10^{11} \mathrm{~W} \mathrm{~cm}^{-2}$ ), and the laser ablation system was coupled to a double-focusing sector field ICP-MS. The capabilities of LA-ICP-MS using "line scan" and "single point" mode at laser energies of 2 and $4 \mathrm{~mJ}$ were compared. Alloy certified reference material (CRM) BAM-328-1 (BAM-Bundesanstalt für Materialprüfung, Berlin, Germany) with a similar matrix composition to the samples investigated was employed to determine the relative sensitivity coefficients (RSCs) of chemical elements to quantify the analytical data. The RSCs of analytes measured by LA-ICP-MS in alloy CRM vary between 0.2 and 2. In addition, other calibration procedures involving calibration curves and solution-based calibration were considered. LA-ICP-MS was used to study the lateral element distribution on NiCrAlY-based alloy and coating after oxidation in air $(300,1000,5000,15000$ hours) at a temperature of $980{ }^{\circ} \mathrm{C}$, whereby an increasing loss of aluminium due to diffusion from coating into the high-temperature base alloy was observed. Furthermore, the diffusion of several substrate alloying elements (e.g., Co, Ta, Mo, W) into the coating after annealing was found, which could be the reason for the alteration of mechanical properties (high-temperature stability) or oxidation performance or both.
\end{abstract}

\section{Introduction}

In many technical applications metallic, alloyed or ceramic construction materials are subject to corrosive, in particular to oxidizing, environments at high temperatures, which results in a deterioration of physical, and especially of mechanical, properties. To reduce the corrosion effects on materials the surface is covered with temperature-resistant coatings, which are protective layers several hundred $\mu \mathrm{m}$ thick. The most commonly used system for high-temperature Ni-based alloys are overlay coatings of the MCrAlY type (with $\mathrm{M}=\mathrm{Ni}$ or $\mathrm{Co}$ ). The base materials are characterized by relatively low chromium content, and the substantial addition of titanium, tantalum, tungsten, etc., frequently results in poor oxidation resistance of the materials. ${ }^{1}$ The development and application of coating systems which guarantee reliable component protection during long-term service is a crucial requirement for this type of material in industrial gas turbines. Interdiffusion between coating and substrate (base material) after oxidation in air at a temperature of $980{ }^{\circ} \mathrm{C}$ for several thousand hours affects the coating life and causes the formation of new, frequently brittle phase at and close to the coating and substrate interface. Several effects, especially the interdiffusion of matrix elements at high temperature, could result in an alteration of the mechanical properties or oxidation performance or both. Therefore, lateral element distribution and diffusion profiles between coating and substrate material are of special interest as a function of oxidation time in air at a temperature of $980{ }^{\circ} \mathrm{C}$.

$\dagger$ Presented at the 2005 European Winter Conference on Plasma Spectrochemistry, January 30-February 3, 2005, Budapest, Hungary.
Different analytical techniques such as secondary ion mass spectrometry (SIMS) and sputtered neutral mass spectrometry $(\mathrm{SNMS})^{2,3}$ are available for the determination of lateral element distribution on cross section surfaces in order to investigate diffusion effects at the interface. However, a major problem in analysis by SIMS is the strong matrix-dependence of the ion yield, which makes SIMS profiles difficult to quantify. ${ }^{4}$ SNMS overcomes some inherent limitations of SIMS by detecting sputtered and ionized neutrals. Glow discharge mass spectrometry (GDMS) and glow discharge optical emission spectroscopy (GD-OES) can also be used for the direct surface analysis of solid samples and depth profiling. ${ }^{5,6}$

Laser ablation inductively coupled plasma mass spectrometry (LA-ICP-MS) has been established in the last few years as a powerful tool for the direct bulk analysis of elements in any solid samples for the determination of trace and ultra-trace impurities down to the sub $\mathrm{ng} \mathrm{g}^{-1}$ concentration level and isotope ratio measurements in quite different fields of science and technology. ${ }^{7-11}$ Furthermore, LA-ICP-MS is a microlocal analytical technique used in materials research and for geological, biological, medical and environmental materials. ${ }^{7,12-15}$ The application of LA-ICP-MS as a surface analytical technique for the determination of lateral element distribution has also been described for ceramic layers, ${ }^{16}$ and for profiling of patterned metal layers. ${ }^{17}$

For the quantification of measured data in LA-ICP-MS mostly standard reference materials were used. For quantification purposes in trace analysis on zeolites, Pickhardt et al. ${ }^{18}$ proposed the use of geological reference materials with a composition similar to samples whereby fused lithium borate targets from both zeolites and reference materials were prepared to improve matrix matching. NIST glass standard 


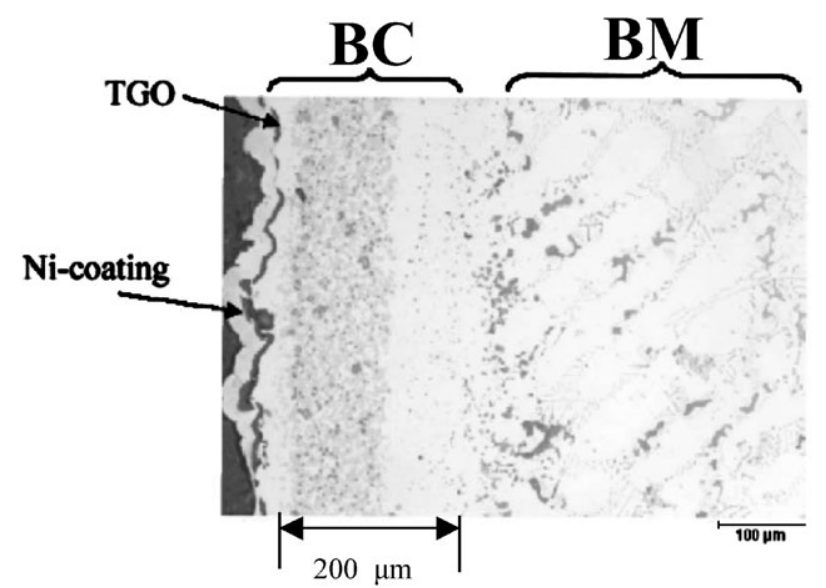

Fig. 1 Bond coat (BC) and base material (BM) layout in analyzed sample.

reference materials are often applied as external calibration standards for the analysis of glasses and geological samples, e.g., basalt glasses. ${ }^{19}$ Jochum et al. ${ }^{11}$ created new reference materials (geological glasses) for microlocal analysis. However, the quantification of analytical results could be a serious problem in LA-ICP-MS, especially if no suitable certified reference material (CRM) is available. Where no matrixmatched CRMs were available, synthetic laboratory standards were prepared, as demonstrated for the quantitative analysis of trace impurities in ceramic layers of solid oxide fuel cells. ${ }^{16}$ Furthermore, CRM-free quantification strategies using solution-based calibration have been developed for the determination of impurities in geological samples, ${ }^{20}$ in silicates ${ }^{21}$ and platinum nanoclusters. ${ }^{22}$

Certified reference materials of similar matrix composition for the quantification of analytical data are available to determine element concentrations in NiCrAlY-based coatings and high-temperature alloys.

The aim of this work is to develop an analytical technique for the characterization of cross section of NiCrAlY-based coatings on high-temperature alloys to study element interdiffusion at interfaces.

\section{Experimental}

\section{Sample and standards}

Cross section of NiCrAlY-based coatings on high-temperature alloys (base material) were analysed by LA-ICP-MS after oxidation in air at a temperature of $980{ }^{\circ} \mathrm{C}$ for $300,1000,5000$ and 15000 hours. Fig. 1 shows a cross section SEM (SEMscanning electron microscopy) graph with the structure of the analyzed sample with bond coat (BC) and base material (BM) layout. The thickness of the bond coat is about $200 \mu \mathrm{m}$.
The initial matrix composition of the sample in bond coat and in base material before oxidation and the composition of the alloy certified reference material BAM-328-1 (Bundesanstalt für Materialprüfung, Berlin) used for quantification with RSCs, and BAM-277-1, BAM-178-1, BAM-128-1, BAM-237-1 used for measurements of calibration curves, are summarized in Table 1 .

\section{Instrumentation}

A double-focusing sector field ICP-MS (Element, Thermo Electron, Bremen, Germany), coupled with a laser ablation system from Bioptic (Ablascope, Bioptic Laser System, Berlin, Germany), was used for the analysis of the lateral element distribution of a cross section of NiCrAlY-based coatings on high-temperature alloy after oxidation in air at a temperature of $980{ }^{\circ} \mathrm{C}$ for various periods. The UV wavelength of a $\mathrm{Nd}$ :YAG laser (5th harmonic, $213 \mathrm{~nm}$ at pulse duration of $5 \mathrm{~ns}$, repetition frequency of $20 \mathrm{~Hz}$, laser power density of $10^{11} \mathrm{~W}$ $\mathrm{cm}^{-2}$, scan velocity $5 \mu \mathrm{m} \mathrm{s}^{-1}$ ) was applied. Using this laser ablation system, the laser spot size can be varied between 5 and $50 \mu \mathrm{m}$. The optimization of the experimental parameters (RF power of ICP and carrier gas flow rate) was performed with respect to the maximum ion intensities of analytes. Optimized experimental parameters of LA-ICP-MS measurements are summarized in Table 2.

\section{Quantification method}

The quantification of mass spectrometric results of lateral element analysis in the cross section of NiCrAlY-based coatings on high-temperature alloy measured by LA-ICP-MS was carried out using BAM-328-1 from BAM (Bundesanstalt für Materialprüfung) as the reference material, whereby relative sensitivity coefficients (RSCs) of elements, defined as the ratio of experimentally measured concentration to certified concentration of element, were determined under the same optimized experimental conditions by LA-ICP-MS and applied as correction factors for the measured values. $\mathrm{Ni}$ was applied as the internal standard element for the quantification procedure. In addition, alternative quantification strategies in LA-ICP-MS via calibration curves and a solution-based strategy were studied.

\section{Results and discussions}

\section{Optimization of surface analytical method}

The surface of certified reference material BAM-328-1 was scanned by a focused laser beam in the "line scan" and "single point" mode to study different sampling methods. The measured ${ }^{27} \mathrm{Al}^{+}$ion intensity as a function of laser ablation time for "line scan" (sample is moved at $5 \mu \mathrm{m} \mathrm{s}^{-1}$ relative to the focused laser beam along a defined line on the sample and laser craters

Table 1 Initial matrix composition of sample in bond coat and in base material (concentration, wt $\%$ )

\begin{tabular}{|c|c|c|c|c|c|c|c|c|}
\hline \multirow[b]{2}{*}{ Element } & \multicolumn{2}{|c|}{ Concentration } & \multicolumn{6}{|l|}{$\mathrm{wt} \%$} \\
\hline & Bond coat & Base material & BAM-328-1 & BAM-327-2 & BAM-277-1 & BAM-178-1 & BAM-128-1 & BAM-237-1 \\
\hline $\mathrm{Ni}$ & 50 & 60 & 20.38 & 19.72 & 10.43 & 0.048 & 0.046 & 10.32 \\
\hline $\mathrm{Co}$ & 25 & 8.3 & 41.65 & 0.16 & 0.15 & - & - & 0.22 \\
\hline $\mathrm{Cr}$ & 17 & 16 & 20.54 & 24.35 & 18.04 & 0.92 & 0.10 & 17.24 \\
\hline $\mathrm{Al}$ & 10 & 3.4 & 0.7 & 0.7 & - & 0.04 & 0.286 & - \\
\hline $\mathrm{Re}$ & 1.5 & - & - & - & - & - & - & - \\
\hline $\mathrm{W}$ & - & 2.5 & 4.16 & - & - & - & - & - \\
\hline $\mathrm{Ta}$ & - & 1.7 & 0.18 & - & - & - & - & - \\
\hline $\mathrm{Ti}$ & - & 3.2 & - & - & - & - & 0.896 & - \\
\hline Мо & - & 1.7 & 4.41 & 0.17 & 0.22 & - & - & 0.306 \\
\hline
\end{tabular}


Table 2 Experimental parameters of LA-ICP-SFMS

\begin{tabular}{|c|c|}
\hline Laser ablation & Ablascope \\
\hline Wavelength/nm & 213 \\
\hline Pulse duration/ns & 5 \\
\hline Repetition frequency $/ \mathrm{Hz}$ & 20 \\
\hline Laser power density/W $\mathrm{cm}^{-2}$ & $8 \times 10^{10}-2 \times 10^{11}$ \\
\hline Energy pulse/mJ & $2-4$ \\
\hline Diameter of laser crater $/ \mu \mathrm{m}$ & 25 \\
\hline Scan velocity $/ \mu \mathrm{m} \mathrm{s}{ }^{-1}$ & 5 \\
\hline ICP-SFMS & ELEMENT \\
\hline Mass resolution, $m / \Delta m$ & 300 \\
\hline $\mathrm{RF}$ power $/ \mathrm{W}$ & 1050 \\
\hline Carrier gas flow rate $/ \mathrm{L} \min ^{-1}$ & 0.92 \\
\hline Dwell time/ms & 50 \\
\hline Sweeps & 1 \\
\hline Replicates & 400 \\
\hline
\end{tabular}

overlap during ablation) and "single point" (continuous ablation at a single point) mode at different laser energies ( $2 \mathrm{~mJ}$ and $4 \mathrm{~mJ}$ ) is shown in Fig. $2 \mathrm{a}$ and $2 \mathrm{~b}$, respectively. During the preablation of the sample surface after starting the measurements, the ion intensity of an analyte increases, as found by the analysis of high-purity quartz glasses in ref. 23. Considering this result the ablation of a cross section of NiCrAlY-based coatings on high-temperature alloy was started outside the bond coat in order to have the stabilized signal when laser beam reaches the bond coat. In general, for higher laser energy higher ion intensities were observed. Smaller laser energy results in better stability of the ion beam and a better precision of analytical data for both sampling methods. The relative standard deviation (RSD in \%) of measured ion intensities at a laser energy of 2 and $4 \mathrm{~mJ}$ on alloy certified reference material BAM-328-1 are compared for "line scan" and "single point" mode in Table 3. In general, using the "line scan" mode the RSDs varied for both laser energies between 8 and $20 \%$. It should be remembered that fractionation effects are possible at lower laser energy. A further loss of ion intensities was

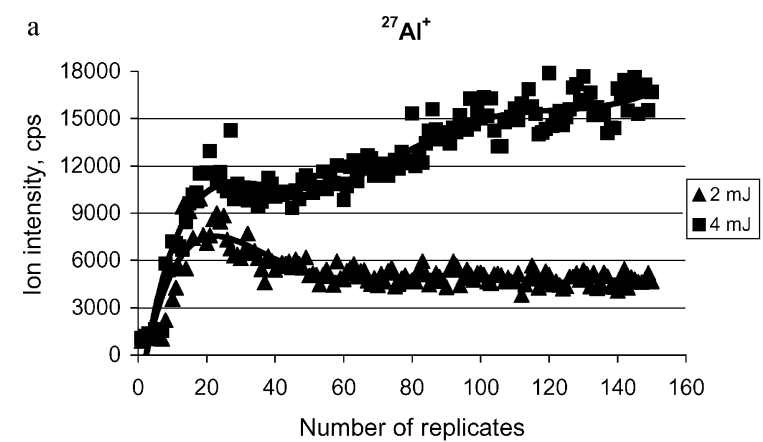

b

${ }^{27} \mathrm{Al}^{+}$

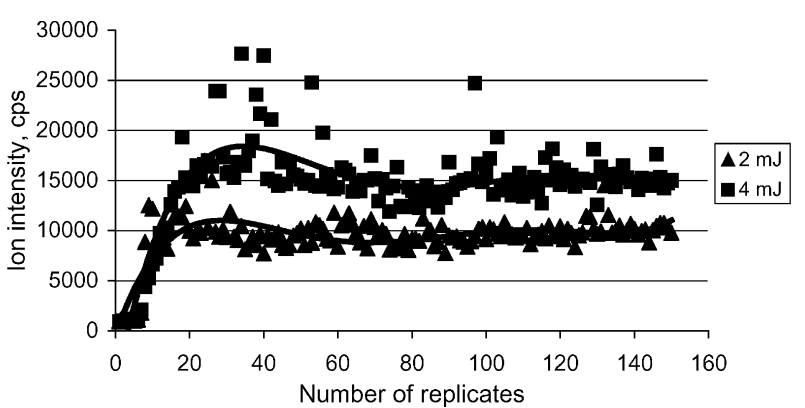

Fig. $2 \mathrm{a},{ }^{27} \mathrm{Al}^{+}$ion intensity as a function of laser ablation time for the surface of certified reference material BAM-328-1 for different laser energies (line scan mode). $\mathrm{b},{ }^{27} \mathrm{Al}^{+}$ion intensity as a function of laser ablation time for the surface of certified reference material BAM-328-1 for different laser energies (single point mode).
Table 3 Relative standard deviation (RSD \%) of measured ion intensities (100 replicates). Measurements were performed using alloy certified reference material BAM 328-1

\begin{tabular}{|c|c|c|c|c|c|c|}
\hline Element & & $\mathrm{Al}$ & $\mathrm{Cr}$ & $\mathrm{Co}$ & $\mathrm{Ni}$ & Mo \\
\hline RSD (\%) line scan mode & $2 \mathrm{~mJ}$ & 10.2 & 8.4 & 9.4 & 8.9 & 20.6 \\
\hline RSD (\%) single point mode & & 12.2 & 9.3 & 19.4 & 16.9 & 31.5 \\
\hline RSD (\%) line scan mode & $4 \mathrm{~mJ}$ & 17.1 & 8.7 & 11.7 & 9.8 & 20.9 \\
\hline RSD (\%) single point mode & & 17.5 & 27.8 & 37.8 & 34.9 & 54.8 \\
\hline
\end{tabular}

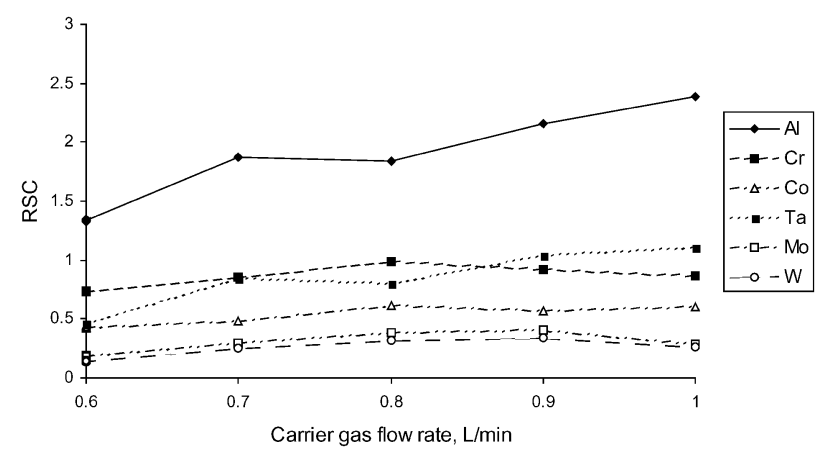

Fig. 3 Dependence of RSCs on the carrier gas flow rate measured by LA-ICP-MS (alloy standard BAM-328-1).

observed if the laser beam was defocused using a "single point" mode due to decreasing laser power density during laser ablation. Also, decreasing the laser power density during laser ablation could be the reason that for elements with high melting point (e.g. Mo) RSDs are higher in comparison with elements with lower melting point.

To study the laser ablation of alloys, the dependence of relative sensitivity coefficients (RSCs) on the carrier gas flow rate and RF power of the ICP were investigated on alloy certified reference material BAM-328-1 by LA-ICP-MS. The results of the measurements are presented in Fig. 3 and Fig. 4, respectively. For all the elements studied no large variation of RSCs as a function of RF power and carrier gas flow rate was found. Values of RSCs varied in the range from 0.2 to 2 , which means that a semi-quantitative determination of elements without reference material is possible with an error factor in this range. Under the experimental condition applied it was observed that elements with high melting point (such as $\mathrm{W}$ and Mo) possess RSCs lower than 1, whereas for $\mathrm{Al}$ as an element with relatively low ionization potential the RSC is higher than one. The relative sensitivity coefficients determined on the certified alloy reference material BAM 328-1 were applied as correction factors for analytical data measured by LA-ICP-MS on the samples.

The certified reference material BAM-327-2 was analyzed by LA-ICP-MS to verify the analytical procedure. The results of

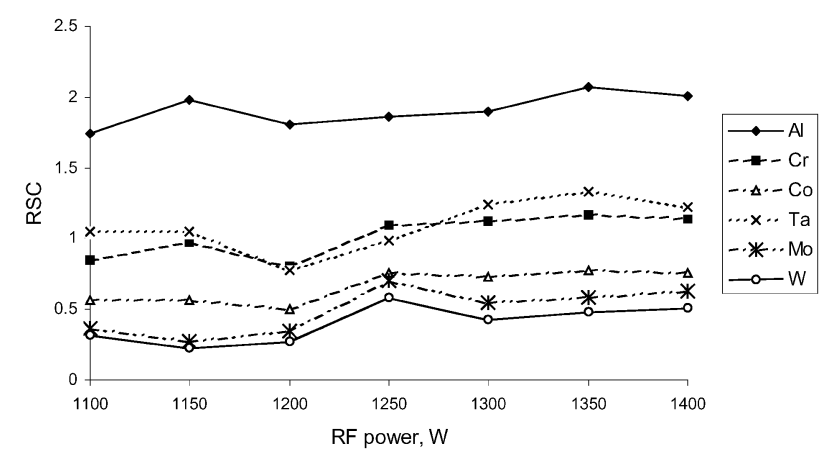

Fig. 4 Dependence of RSCs on the RF-power measured by LA-ICPMS (alloy standard BAM-328-1). 


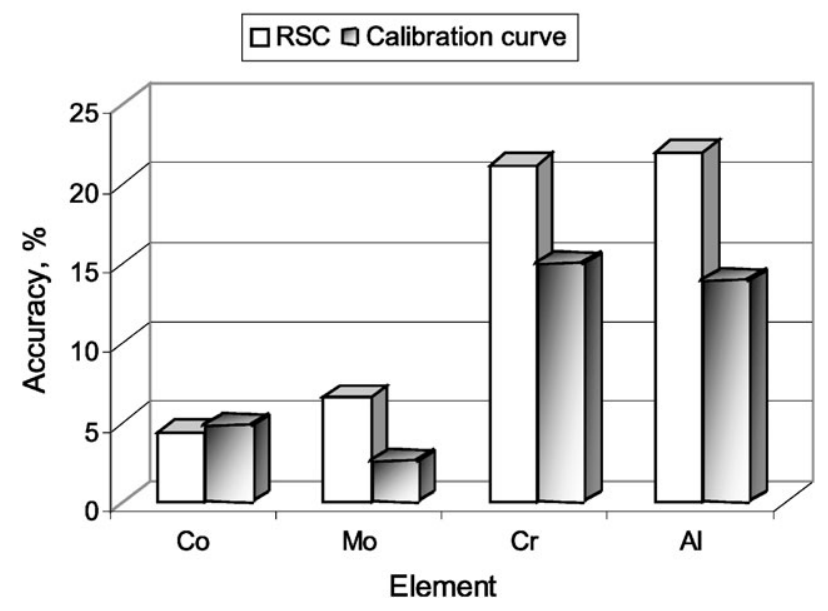

Fig. 5 Accuracy of quantitative element determination in CRM BAM-327-2 using RSCs for correction of measured values.

bulk analysis on CRM BAM-327-2 yielded an accuracy between 4 and $22 \%$ in the alloy, as demonstrated in Fig. 5.

Further possible calibration strategies using calibration curves and solution-based calibration were studied. As a result, correlation coefficients $\left(R^{2}\right)$ of the calibration curves measured in the "single point" mode and "line scan" mode by LA-ICPMS at $2 \mathrm{~mJ}$ energy of the laser beam are presented in Fig. 6. Analysis of CRM BAM-327-2 using calibration curves for quantification generally yields better accuracy in comparison with the RSC quantification method (see Fig. 5), but the technique is more time-consuming and the possibility of quantification is limited by the availability of certified elements in alloy standards.

Elements which are not certified in standard reference materials will be quantified by solution-based calibration using an ultrasonic nebulizer (USN), as described in ref. 20. In Fig. 7 the distribution of $\mathrm{Ti}$ in the sample after 1000 hours oxidation time is shown. Mo was used as the internal standard element. Measured Ti concentration varied between 3.2 and 3.5\%; the

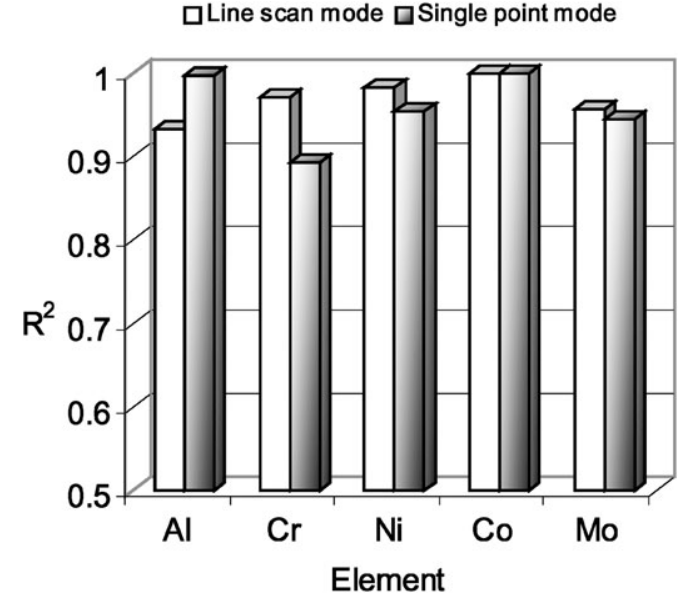

Fig. 6 Correlation coefficient $\left(R^{2}\right)$ of the calibration curve measured in "single point" mode and "line scan" mode by LA-ICP-MS at $2 \mathrm{~mJ}$ energy of laser beam.

Ti

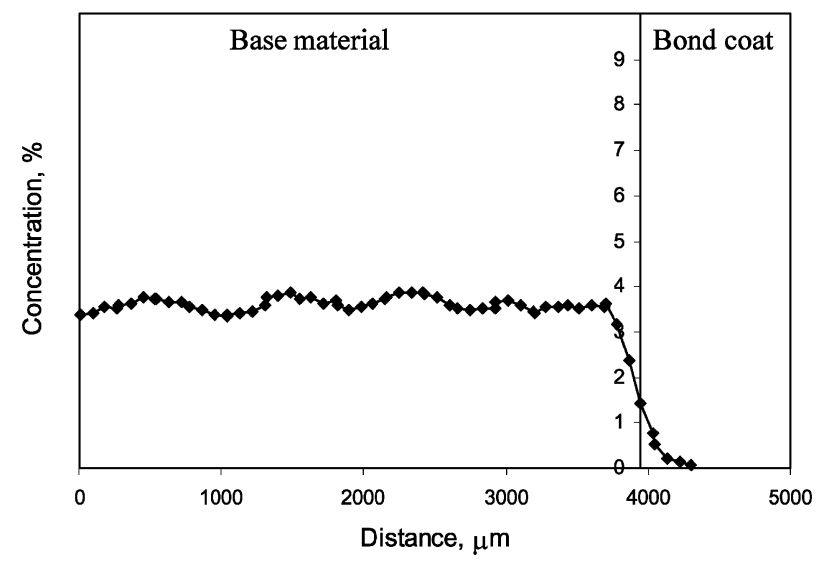

Fig. 7 Ti distribution in the sample after 1000 hours of oxidation time measured by LA-ICP-MS (quantification via solution-based calibration).
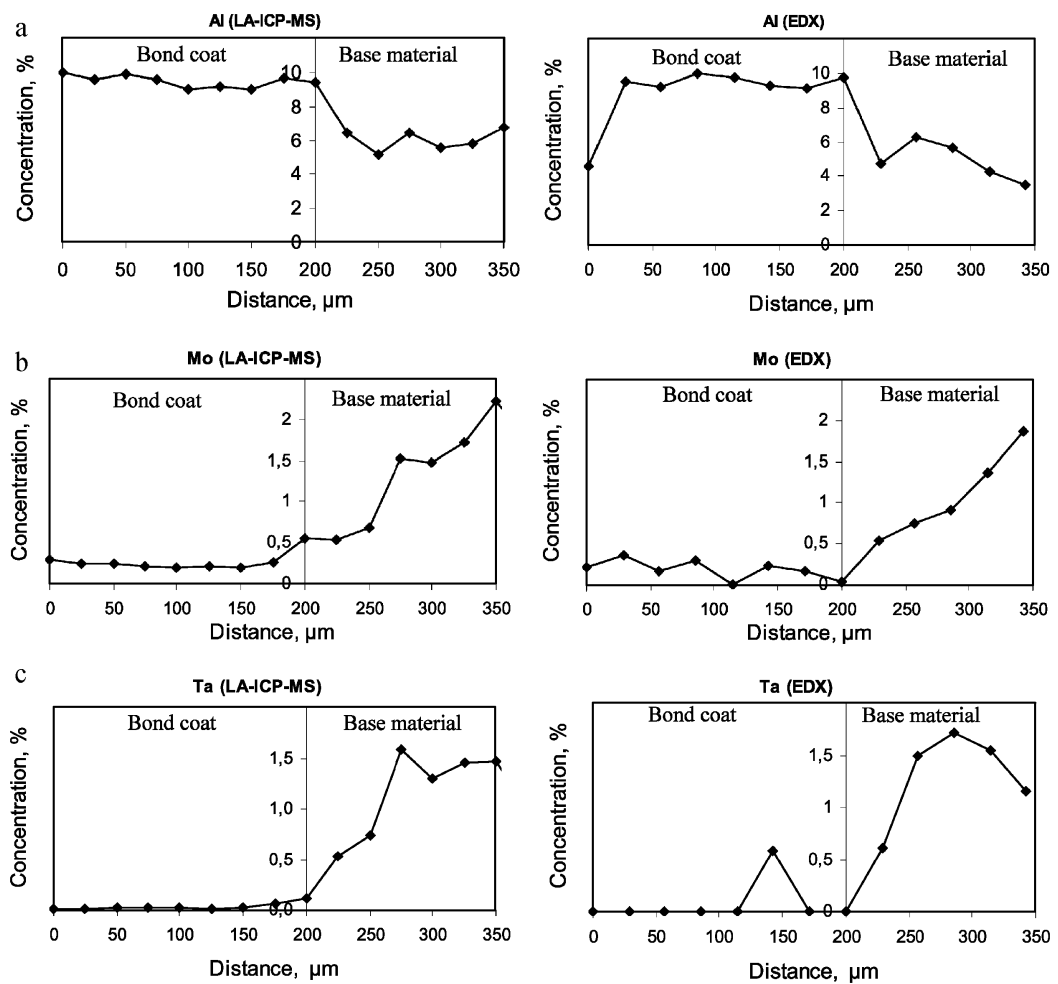

Fig. 8 Comparison of the quantitative determination of $\mathrm{Al}$ (a), Mo (b) and Ta (c) by LA-ICP-MS and EDX in a sample after $1000 \mathrm{~h}$ oxidation in air at $980{ }^{\circ} \mathrm{C}$ 


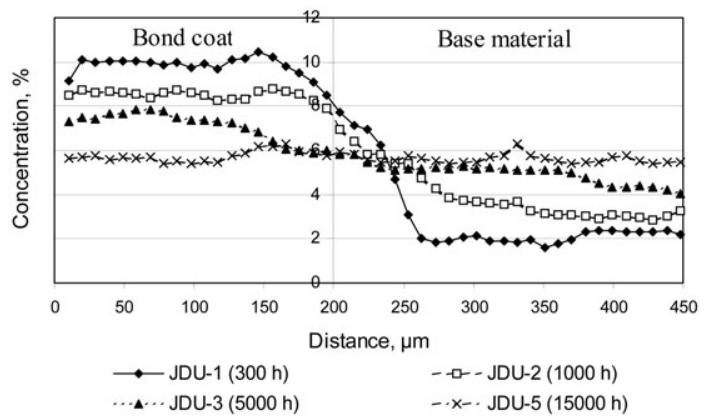

$\mathrm{Cr}$
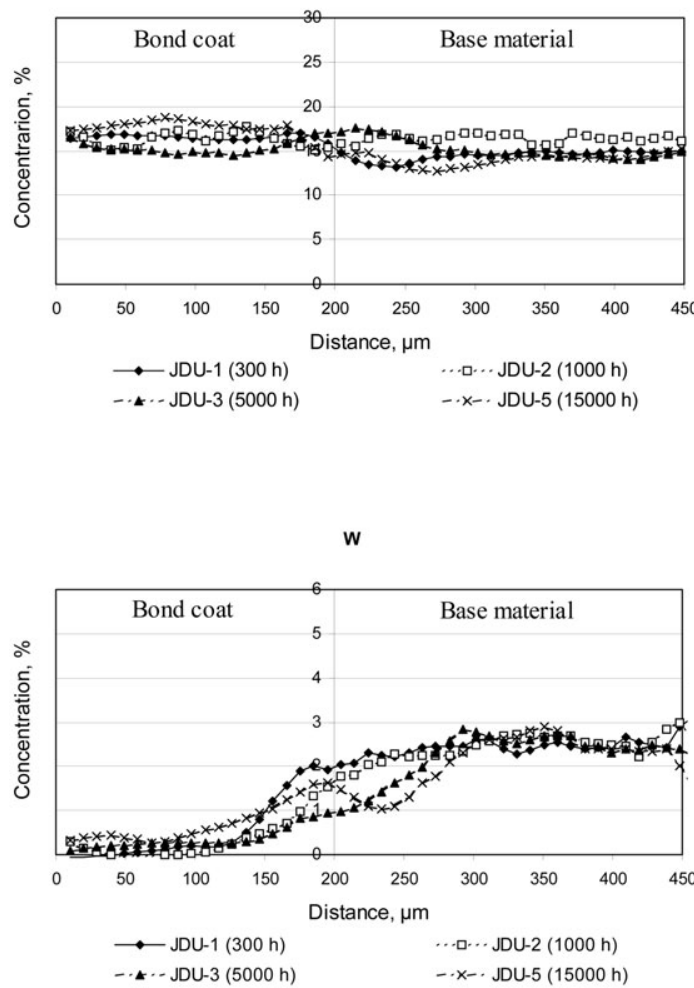

Co

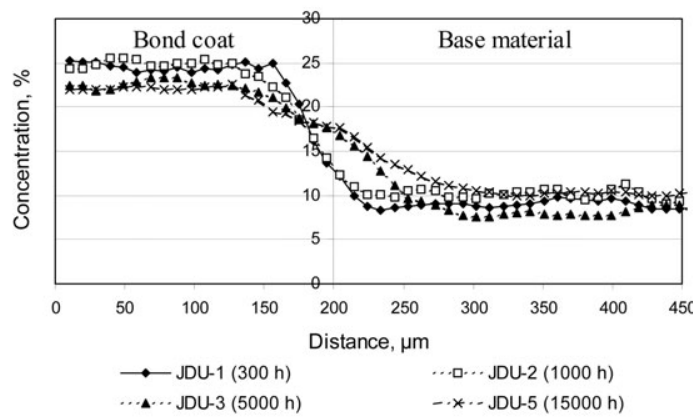

Mo

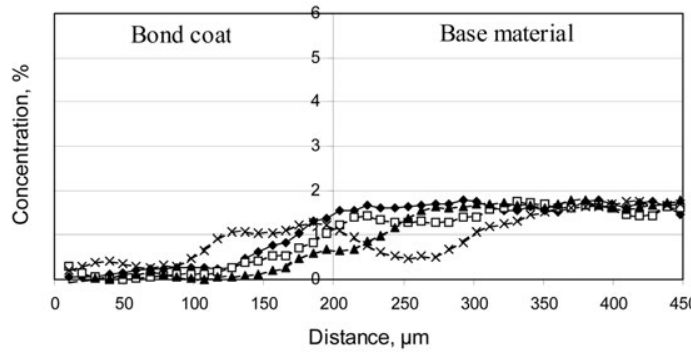

$\rightarrow J D U-1(300 h) \quad--2-J D U-2(1000 h)$

-...JDU-3 $(5000 \mathrm{~h}) \quad$-.*..JDU-5 $(15000 \mathrm{~h})$

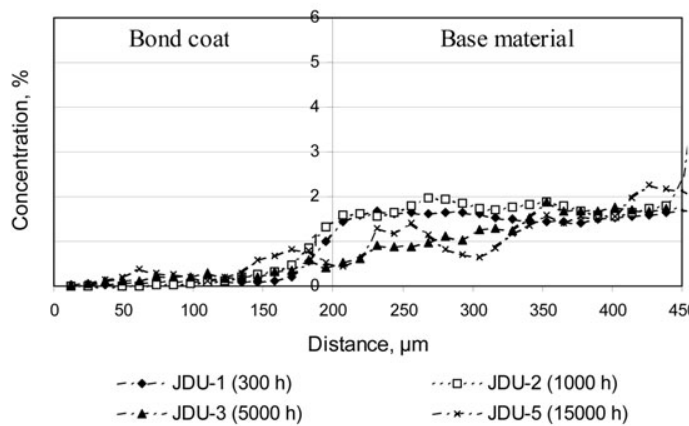

Fig. 9 Distribution of $\mathrm{Al}$ (a), Co (b), Cr (c), Mo (d), W (e) and Ta (f) in the sample after different oxidation times, measured by LA-ICP-MS.

known concentration of $\mathrm{Ti}$ in the base material in the sample before oxidation in air is $3.2 \%$.

\section{Lateral element distribution of cross section of NiCrAlY-based coatings on high-temperature alloy}

The analytical method was evaluated by comparison with EDX (EDX - energy dispersive X-rays analysis) measurements. Measurements by "single point" mode were performed for the NiCrAlY-based coatings on a high-temperature alloy after oxidation in air at a temperature of $980{ }^{\circ} \mathrm{C}$ for 1000 hours only and these results were compared with EDX measurements for some elements. Good agreement between LA-ICP-MS and EDX techniques was found (Fig. 8).

The results of the lateral Al, Co, Cr, Mo, W and Ta distribution in NiCrAlY-based coatings on high-temperature alloy after oxidation in air at a temperature of $980{ }^{\circ} \mathrm{C}$ for 300 , 1000, 5000 and 15000 hours are presented in Fig. 9. LA-ICPMS measurements were performed under optimized conditions in the "line scan" mode. In Fig. 9, the concentrations of alloy elements are shown as a function of distance from 0 to $500 \mu \mathrm{m}$ in a cross section of NiCrAlY-based coatings on a high- temperature alloy. The bond coat is located from $0-200 \mu \mathrm{m}$ the base alloy is from $200-500 \mu \mathrm{m}$.

From Fig. 9, the interdiffusion of elements (Al, Co, Mo, W and $\mathrm{Ta}$ ) between coating and substrate material was observed. Such interdiffusion affects the coating life mainly in the following ways: aluminium loss due to diffusion from coating into the base metal and diffusion of substrate alloying elements into the coating layer, thereby altering the mechanical properties, or oxidation performance, or both.

Future studies will be focused on microlocal analysis in thin alloyed samples in order to study homogeneity and inclusions in alloys. Quantitative analysis using LA-ICP-MS with liquid calibration will be applied for this task.

\section{Conclusions}

LA-ICP-MS has become one of the most powerful methods for direct analysis in layered and interface analysis on alloyed samples. Quantification is possible using relative sensitivity coefficients (RSCs), calibration curves and applying the solution-based calibration technique. The accuracy of the analytical results obtained via RSCs, between 4-22\%, demonstrates the capability of the applied technique. 


\section{Acknowledgements}

The authors would like to express their gratitude to H.-J. Dietze (Jülich) for valuable discussions.

\section{References}

1 W. J. Quadakkers, 7th Polish Corrosion Conference, KOROZJA 2002, June, Kraków, Poland, 2002, pp. 17-21 .

2 J. S. Becker and H.-J. Dietze, Int. J. Mass Spectrom., 2000, 197, 1.

3 H. Nickel, W. J. Quadakkers and L. Singheiser, Anal. Bioanal. Chem., 2002, 374, 581

4 W. J. Quadakkers and H. Viefhaus, EFC Publications 14, Guidelines for Methods of Testing and Research in High Temperature Corrosion, London, 1995, 189.

5 A. I. Saprykin, J. S. Becker, U. Crone and H.-J. Dietze, Fresenius J. Anal. Chem., 1997, 358, 145.

6 V. Hoffman, R. Kurt, K. Kammer, R. Thielsch, Th. Wirth and U. Beck, Appl. Spectrosc., 1999, 53, 987.

7 J. S. Becker, Spectrochim. Acta, Part B, 2002, 57, 1805.

8 S. F. Durrant, J. Anal. At. Spectrom., 1999, 14, 1385.

9 J. S. Becker and H.-J. Dietze, Int. J. Mass Spectrom., 2003, 228, 227.

10 C. Pickhardt, H.-J. Dietze and J. S. Becker, Int. J. Mass Spectrom., 2005, 242, 273.
11 K. P. Jochum, B. Stoll, K. Herwig, M. Amini, W. Abouchami and A. W. Hofmann, Int. J. Mass Spectrom., 2005, 242, 281.

12 J. B. Murphy, J. Fernandez-Suarez, T. E. Jeffries and R. A. Strachan, J. Geol. Soc., 2004, 161, 243.

13 T. Prohaska, C. Latkoczy, G. Schultheis, M. Teschler-Nicola and G. Stingeder, J. Anal. At. Spectrom., 2002, 17, 887.

14 M. Zoriy, M. Kayser, A. Izmer, C. Pickhardt and J. S. Becker, Int. J. Mass Spectrom., 2005, 242, 297.

15 J. S. Becker, M. Zoriy, C. Pickhardt, N. Palomero-Gallagher and K. Zilles, Anal. Chem., 2005, in the press.

16 J. W. Westheide, J. S. Becker, R. Jäger and H.-J. Dietze, J. Anal. At. Spectrom., 1996, 11, 661.

17 M. Bi, A. M. Ruiz, I. Gornushkin, B. W. Smith and J. D. Winefordner, Appl. Surf. Sci., 2000, 158, 197.

18 C. Pickhardt, I. J. Brenner, J. S. Becker and H.-J. Dietze, Fresenius' J. Anal. Chem., 2000, 368, 79.

19 P. J. Sylvester and S. M. Eggins, Geostand. Newsl., 1997, 21/2, 215.

20 C. Pickhardt, J. S. Becker and H.-J. Dietze, Fresenius' J. Anal. Chem, 2000, 368, 173

21 L. Halicz and D. Guenther, J. Anal. At. Spectrom., 2004, 19, 1539 .

22 J. S. Becker, C. Pickhardt and W. Pompe, Int. J. Mass Spectrom., 2004, 237, 13.

23 J. S. Becker and D. Tenzler, Fresenius' J. Anal. Chem., 2001, 370 637. 